\title{
Modeling of Vacuum Drying of Licorice (Glycyrrhizia glabra) Roots
}

\author{
Ahmad Kouchakzadeh* \\ Department of Biosystems Engineering, Ilam University, Ilam, Iran \\ Received: March 2019
}

Accepted: May 2019

\section{A B S T R A C T}

Background and Objectives: Desiccation is a necessary procedure to eliminate moisture from foodstuffs in industries, especially pharmaceutical, food and tobacco industries. In the present study, a mathematical modeling was assessed for vacuum drying of the licorice roots.

Materials and Methods: Fresh licorice roots were dried at 50 mbar. Temperatures included 22to $150^{\circ} \mathrm{C}$ and diameters of roots included 10 and $15 \mathrm{~mm}$. A layer of licorice roots was transferred to a dish of balance on vacuum dryer and then changes in weight were recorded and moisture contents were calculated at various times.

Results: Five mathematical models were adapted to empirical data. Curve expert has been used as statistical calculation. It was proved that the empirical two term's model with high values of $\mathrm{R}^{2}=98.21 \%$ was suitable for 10 -mm diameter and Henderson Pabis model with $\mathrm{R}^{2}=95.43 \%$ for $15-\mathrm{mm}$ diameter roots.

Conclusions: The two term and Henderson Pabis models were assessed by comparing coefficients of determination and standard error between the monitored and forecasted moisture ratios.

Keywords: Modeling, Vacuum drying, Licorice root

\section{Introduction}

Although synthetic antioxidants include high efficiency and relative cheapness, their use decreases due to their carcinogenicity. Therefore, research studies have focused on antioxidants from natural sources in recent years. Licorice, the root of Glycyrrhiziaglabra, has been used in medicine as a natural antioxidant for more than 2000 years. Licorice root has widely been used in pharmaceutical, food and tobacco industries (1). Licorice, best grown in well-drained soils in sunny deep valleys, is harvested in autumns two to three years after planting. Usual yield of the fresh roots includes 20-50 t/ha per harvest. Iran ranked second in 2017in production of licorice with nearly 170,000 ha of culture areas (2).The root is simply harvested, washed and dried. Licorice root has been used in many forms, either containing glycyrrhizin or as DGL, deglycyrrhizinated licorice. When licorice roots is collected, the following processes of cleaning of dirt, drying to proper moisture for preservation, crushing to small pieces, boiling at high pressures, and filtering, concentrating and packing in cubes of the extracts are carried out (Figures1 and 2). The licorice cubes are mainly exported to China, India, Russia and European Union. Drying is the most important stage in licorice root processing. Nearly all fresh licorice roots (with nearly 40-50\% moisture content, wet basis) should be moisture removed to low contents (3-5\%) in very short-time after harvest (3).The common drying method used in licorice root industries is shade drying. Disadvantages of this procedure include long drying times and that the desiccation time cannot be decreased by raising the drying temperature since many ingredients of licorice roots are highly heat sensitive. Studies have focused on effects of environmental factors on growth of licorice roots (4-6). A few studies have been carried out on medicinal compounds of licorice roots during the drying process. Sabetkalam and Ghasemi (7) showed that convective air-drying of Iranian licorice roots at $22^{\circ} \mathrm{C}$ resulted minimum oxidative stress and maximum antioxidant activity of 0.084 and $91.52 \%$, respectively. They reported that drying above $22^{\circ} \mathrm{C}$ decreased antioxidant activities. Compared to shade 
drying, ambient temperature forced air-drying and vacuum low-temperature drying could extremely decrease drying time of sensitive plants with no damages in quality characteristics of the final products. Forced convective air-drying at ambient temperatures removes humidity. When substances are dried with no heat forced air, the natural drying possibility is achieved. The procedure is slow and weather-dependent. A wise method "fan off-fan on" is planned, considering subsequent situations of air temperature, relative humidity and moisture content and temperature of the dried material. Licorice roots are further dried using this method and the total time (involving fan off and on times) may complete from one week to several months if a winter repose can be permitted in cold regions. Vacuum drying is a mass transfer operation; from which, moisture is removed when generally wet matters are discharged by producing low atmospheric pressures. In food and pharmaceutical industries, desiccation is a necessary procedure to eliminate humidity from materials. Vacuum dehydration is mostly used for the materials that are heat sensitive. When pressure is decreased, boiling point of water decreases and rate of process of releasing moisture rises significantly; hence, enlarging dehydration rate. Because of a high-energy consumption in this method, vacuum drying should be used insensitive and high-value added foodstuffs (8).There are many studies on effects of vacuum drying on various food products and plants such as bananas (9), potatoes (10), mushrooms (11), pumpkins (12), red peppers (13), onions (14) and pistachios (15). However, there are a few studies on how the oxidative stress and antioxidant activity are affected by drying at low-temperature vacuum conditions. Therefore, the objective of the current study was modeling the vacuum drying kinetics of licorice roots. To the authors' best knowledge, no similar investigations have been carried out on licorice roots. Development of vacuum drying procedures for high-quality dehydrated licorice root production in proportionately short times can favor licorice industries.

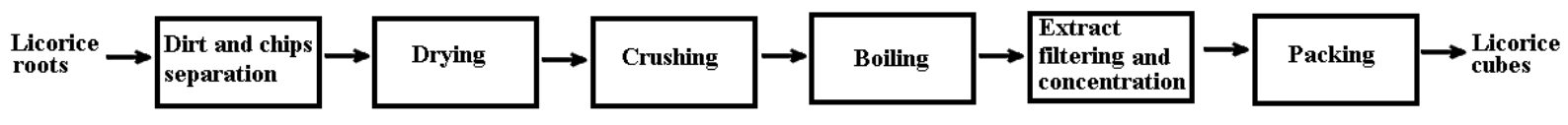

Figure1. Schematic of licorice root processing in Iran

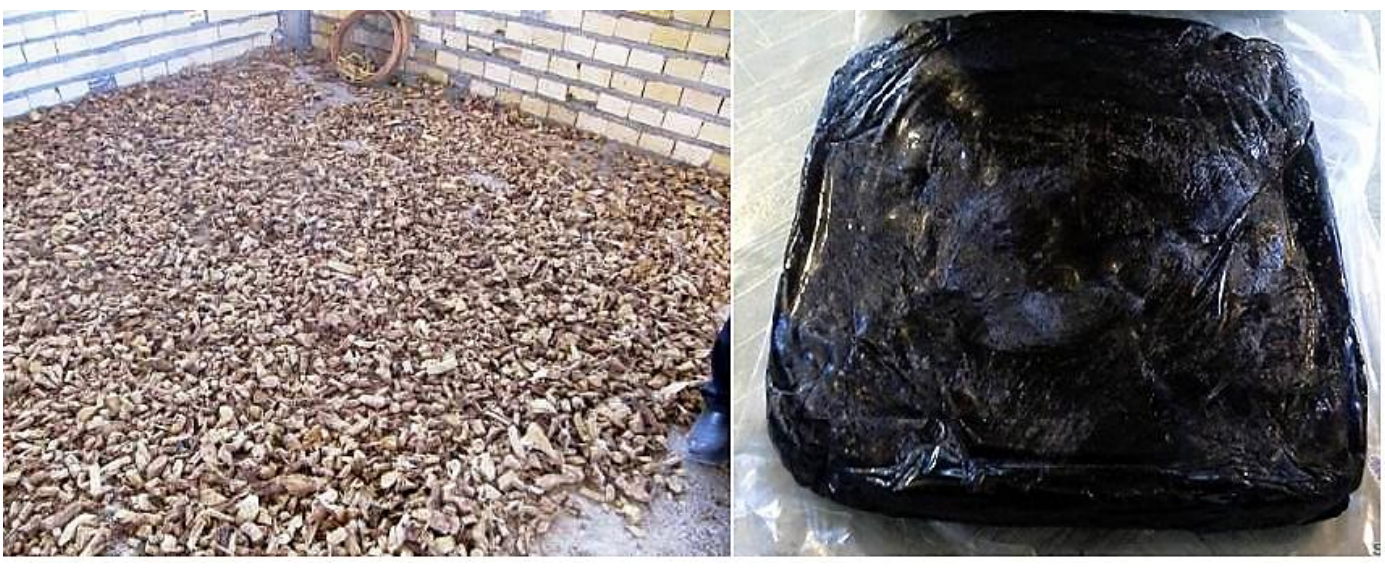

Figure2. Licorice roots in thin layers for shade drying (left) and extract (right) 


\section{Materials and Methods}

The licorice roots were purchased from Zagros Licorice, Kermanshah, Iran. Fresh licorice roots were stored at $4{ }^{\circ} \mathrm{C}$ until use. Nearly $200 \mathrm{~g}$ of the fresh licorice roots were collected before the beginning of each drying run based on their diameters (10 and 15 $\mathrm{mm})$. Roots were washed to remove dirt. Then, $100 \mathrm{~g}$ of the roots were used for drying test, while the rest were used for the moisture assessment. The first moisture assessment of licorice roots was carried out using oven at $130^{\circ} \mathrm{C}$ for $6 \mathrm{~h}$ under standard method of ASABE (16). Briefly, $100 \mathrm{~g}$ of licorice roots were transferred to an oven, the -final weight was recorded and the decreased weight was calculated as gram water per gram dry matter.

Experimental procedure: Structure of the vacuum oven is illustrated in Figure3. The apparatus is made of a vacuum drying oven (Model VO 400 Memmert, Germany) and an electronic weight device (ETRONIX, Poland) inside the vacuum oven for measurements. Data were wirelessly transferred via an IR system to a laptop. Weight broadcasts sent weight and temperature to the laptop every 1 or 10 min, depending on the switch status. The weight included a battery power supply and an accuracy of $0.01 \mathrm{~g}$. The vacuum was regulated using electronic solenoid valves with adjusting ranges of $10-1100$ mbar with resolution of 1 mbar.

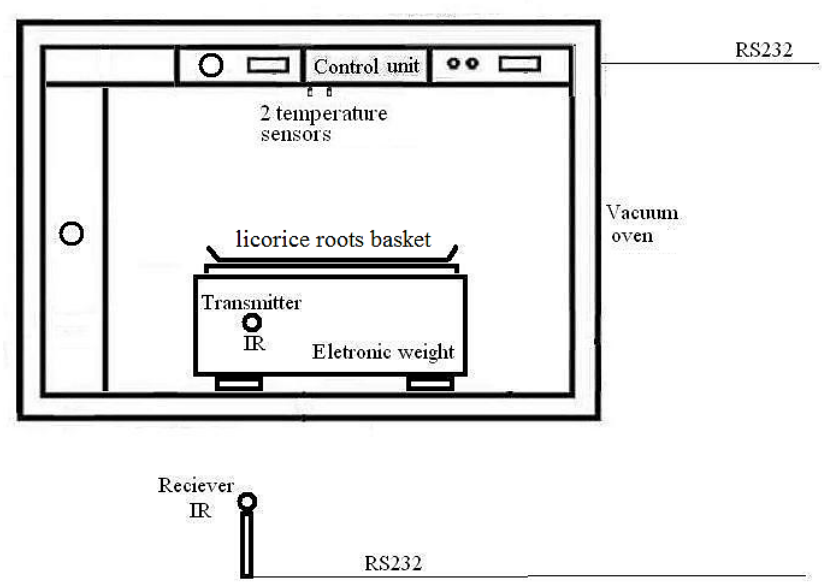

Figure3. Schematic diagram of the laboratory vacuum dryer

Drying temperature was monitored using two highgrade platinum temperature pt100 sensors with sensitivity of $\pm 1{ }^{\circ} \mathrm{C}$. For each vacuum drying test, licorice roots were transferred to dishes of weight on vacuum dryer and then changes in licorice root weight were recorded automatically and moisture contents were calculated. The drying temperature was regulated at $22{ }^{\circ} \mathrm{C}$ and the base vacuum at 50 mbar.

Calculations: The moisture ratio $\left(\mathrm{M}_{\mathrm{R}}\right)$ was calculated based on the following equation of 1 :

$$
M_{R}=\frac{M-M_{e}}{M_{0}-M_{e}}
$$

Where, $\mathrm{M}, \mathrm{M}_{0}$ and $\mathrm{M}_{\mathrm{e}}$ (g water/g dry matter) were existent, initial and dynamic equilibrium wetness, respectively. When equilibrium wetness could be surmised zero for the vacuum drying, then the moisture ratio could be reorganized as $\mathrm{M} / \mathrm{M}_{0}(17)$.

Moisture ratio curves were fitted with five empirical models, which were used later in herb drying kinetic such as Scutellaria (15), basil (18), Andrographis paniculata (19), yerba mate leaf (20), amaranth (21), Steviarebaudianabertoni leaf (22), ginger (23) and other herb dryings. These models were called Newton, Page, Henderson Pabis, Logarithmic and Two term described in equations 2 6, respectively:

$M_{R}=\exp (-k t)$

$M_{R}=\exp \left(-k t^{n}\right)$

$M_{R}=a \exp \left(-k t^{n}\right)$

$M_{R}=a \exp (-k t)+c$

$M_{R}=a \exp \left(-k_{0} t\right)+b \exp \left(-k_{1} t\right)$

Where, $\mathrm{t}$ was the time (min) and $\mathrm{k}, \mathrm{k}_{0}, \mathrm{k}_{1}, \mathrm{n}, \mathrm{a}, \mathrm{b}$ and $\mathrm{c}$ were the model parameters.

Non-linear regression analyses were carried out using Statgraphics Centurion XVII Software. Evaluations of the model's compliance were carried out using coefficients of determination $\mathrm{R}^{2}$ andstandard error of the estimate $S_{\mathrm{e}}$ calculated by the software.

\section{Results and Discussion}

Drying curves: The initial moisture of licorice roots included $48.2 \%$ (wb). The moisture instead of time curves for licorice root drying affected by size (10 and $15-\mathrm{mm}$ diameters) are displayed in Figure4. Clearly, as size of the roots increased, time for reaching specific moisture levels increased. For example, dehydration time for arriving $10 \%$ (wb) moisture content of the roots with 10 and $15-\mathrm{mm}$ diameters included 40 and $110 \mathrm{~min}$, respectively. 
These results have been reported for the vacuum drying of parsley (24) and American ginseng roots (25). When diameters of the roots increased, the drying time increased as well. As seen in Figure4, fast decreases in moisture drop of the licorice roots were observed in the first $20 \mathrm{~min}$ of vacuum starting. Drying then continued with a gentle slope. This could occur by capillary attribute and cell structure of the licorice roots as signified by drying rates, which were not steady. During the initial $20 \mathrm{~min}$, the external layer of the roots conducted as a surface of free water when exposed to vacuum. The value of moisture elimination of the surface relied on standing where drying occurred until after $20 \mathrm{~min}$ of wetness migration from the interior layer of roots to the exterior layer. The final phase relied on diffusion rate of moisture in vacuum from the root inside to the surface layer and moisture reduction from the root surface layer.

Modeling drying curves: Data from the vacuum desiccation were used to assess suitability of equations 3-7. Model parameters were calculated using nonlinear regression. Results are illustrated in Tables 1 and 2. The analysis resulted two term models with high values of $\mathrm{R}^{2}=98.21 \%$ for 10 -mm diameter root drying (Table 1). The fitness is demonstrated in Figure 5. The $\mathrm{R}^{2}$ value for $15-\mathrm{mm}$ diameter root drying included $95.43 \%$ for Henderson Pabis models that signified excellent suitability of the models (Table 2). The fitness is shown in Figure 6.

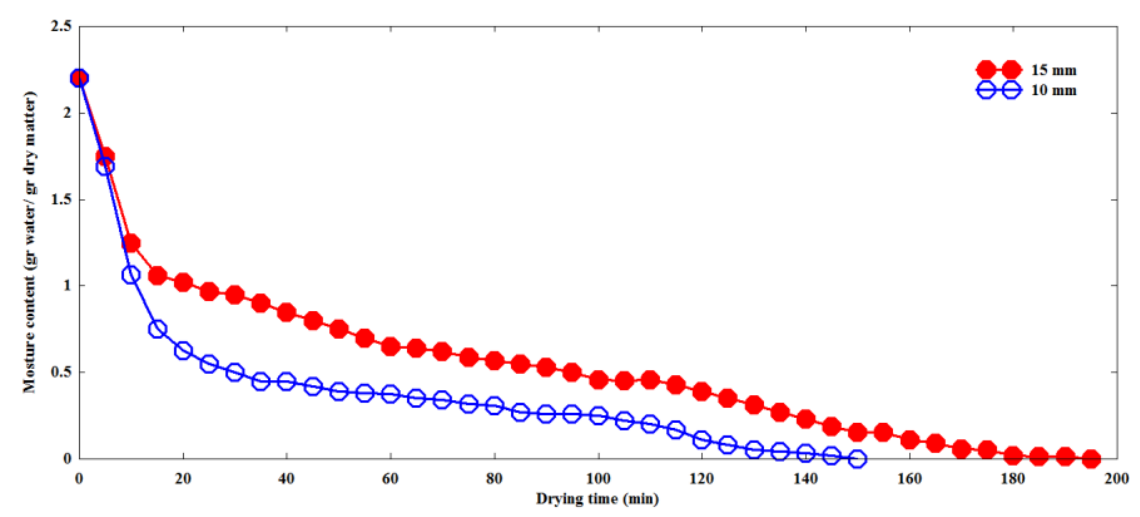

Figure4.Vacuum drying curve for 10 and $15 \mathrm{~mm}$ diameters of the licorice roots

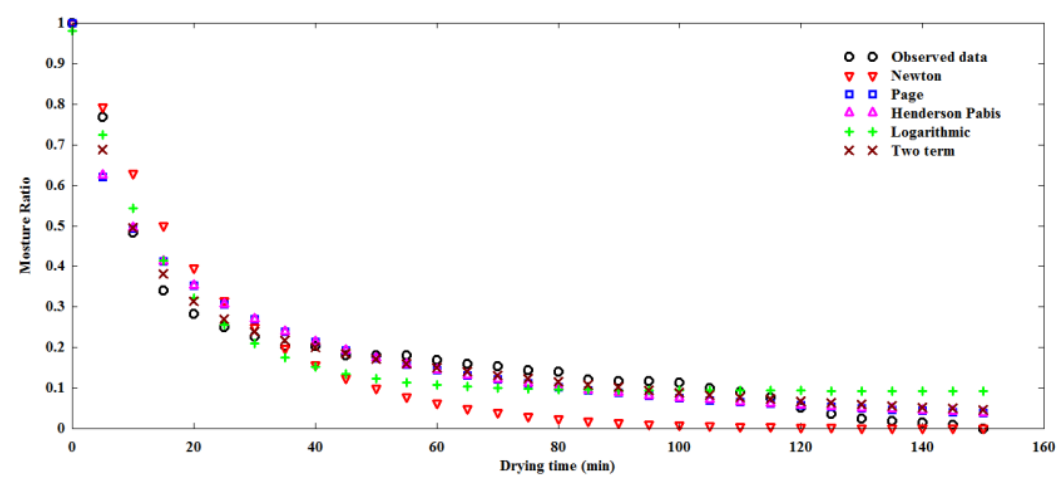

Figure5. Variations of moisture ratios by various drying models instead of time for 10-mm diameter licorice root specimens in vacuum 


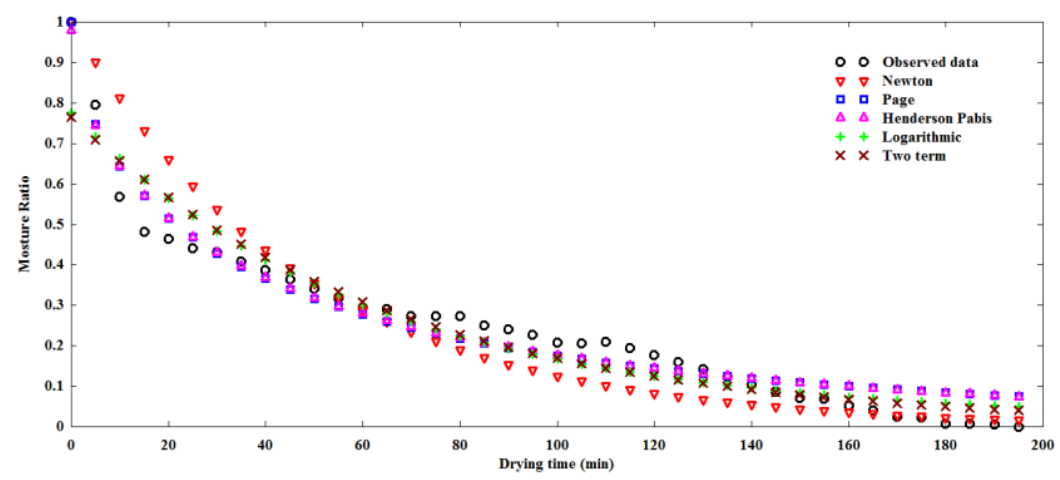

Figure6. Variations of moisture ratios by various drying models instead of time for 15-mm diameter licorice root specimens in vacuum

Table 1. Model parameters in vacuum drying of $10-\mathrm{mm}$ diameter licoric roots

\begin{tabular}{llccc}
\hline Model & Parameter & Value & $\mathrm{R}^{2}$ & $\mathrm{~S}_{\mathrm{e}}$ \\
\hline Newton & $\mathrm{k}$ & 0.0461323 & $83.97 \%$ & 0.0855525 \\
Page & $\mathrm{n}$ & 0.563652 & & \\
& $\mathrm{k}$ & 0.192644 & $95.96 \%$ & 0.0436636 \\
Henderson & $\mathrm{a}$ & 1.02202 & & \\
Pabis & $\mathrm{n}$ & 0.554847 & $96.01 \%$ & 0.0442038 \\
& $\mathrm{k}$ & 0.202154 & & \\
Logarithmic & $\mathrm{a}$ & 0.886678 & & \\
& $\mathrm{c}$ & 0.0932358 & $94.16 \%$ & 0.0534725 \\
& $\mathrm{k}$ & 0.0677995 & & \\
Two term & $\mathrm{a}$ & 0.701144 & & \\
& $\mathrm{~b}$ & 0.328392 & $98.21 \%$ & 0.0301594 \\
& $\mathrm{k}_{0}$ & 0.122232 & & \\
\hline
\end{tabular}

Table 2. Model parameters in vacuum drying of 15-mm diameter licoric roots

\begin{tabular}{lllll}
\hline Model & Parameter & Value & $\mathrm{R}^{2}$ & $\mathrm{~S}_{\mathrm{e}}$ \\
\hline Newton & $\mathrm{k}$ & 0.0207124 & $82.08 \%$ & 0.0907287 \\
Page & $\mathrm{n}$ & 0.597261 & & \\
& $\mathrm{k}$ & 0.111129 & $95.39 \%$ & 0.0466508 \\
Henderson & $\mathrm{a}$ & 0.978618 & & \\
Pabis & $\mathrm{n}$ & 0.611311 & $95.43 \%$ & 0.0470627 \\
& $\mathrm{k}$ & 0.102823 & & \\
Logarithmic & $\mathrm{a}$ & 0.757752 & & \\
& $\mathrm{c}$ & 0.0181971 & $91.79 \%$ & 0.0630257 \\
& $\mathrm{k}$ & 0.0162985 & & \\
Two term & $\mathrm{a}$ & 0.382634 & & \\
& $\mathrm{~b}$ & 0.382634 & $91.78 \%$ & 0.0639836 \\
& $\mathrm{k}_{0}$ & 0.0151207 & & \\
\hline
\end{tabular}

\section{Conclusion}

Low-temperature vacuum drying method can help solve essentialness in licorice root processing. This study has shown that drying at 50 mbar vacuum and
$22{ }^{\circ} \mathrm{C}$ temperature decreases drying time by $150-195$ min according to root diameters. The empirical two term and Henderson Pabis models adequately described the vacuum drying data.

\section{Acknowledgement}

The author gratefully acknowledges Zagros Licorice, Kermanshah, Iran.

\section{References}

1. Craig, W J. Health-promoting properties of common herbs. Am J Clin Nutr. 1999; 70(3):491-499.

2. http://dolat.ir/detail/291167 accede at June 10, 2017

3. Nesterenko, AA., Kenijz, NV., Shlykov SN. Biological assessment of summer sausage with preprocessing for starter cultures and meat raw by electromagnetic field of low frequencies. Res J Pharm Biol Chem Sci. 2016; 7(1):1214-20.

4. Afreen, F., Zobayed, S.M.A., Kozai, T. Spectral quality and UV-B stress stimulate glycyrrhizin concentration of Glycyrrhizauralensis in hydroponic and pot system. Plant Physiol Biochem. 2005; 43(12):1074-1081.

5. Hou, J.L., Li, W.D., Zheng, Q.Y., Wang, W.Q., Xiao, B. Xing, D. Effect of low light intensity on growth and accumulation of secondary metabolites in roots of GlycyrrhizauralensisFisch. Biochem Syst Ecol. 2010; 38(2):160-168.

6. Rui, S.U.N., Hikosaka, S., Sawada, H., Saito, T., Tadashi, K.U.D.O., Takako, O.H.N.O., Yoshimatsu, K., Kawano, N., Kawahara, N. Effects of Post-harvest Storage and Drying Temperatures on Four Medicinal Compounds in the Root of Chinese Licorice (Glycyrrhizauralensis). ECB (Environmental Control in Biology). 2014; 51(4):149-155.

7. Sabetkalam, M., Ghasemi, N. The effect of drying temperature and storage of licorice roots on its antioxidant capacity. National Conference on natural products and medicinal plants, 2012. 
http://journals.nkums.ac.ir/index.php/ndnkh/article/vie w/722 accede at June 11, 2017

8. Kouchakzadeh, A., Haghighi, K. Modeling of vacuuminfrared drying of pistachios. Agric Eng Int: CIGR Journal. 2011; 13(3):1-6.

9. Nimmol, C., Devahastin, S., Swasdisevi, T., Soponronnarit, S. Drying of banana slices using combined low-pressure superheated steam and farinfrared radiation. J Food Eng. 2007; 81(3):624-33.

10. Bundalevski, S., Mitrevski, V., Lutovska, M., Geramitcioski, T., Mijakovski, V. Experimental investigation of vacuum far-infrared drying of potato slices. J Process Energy Agric. 2015;19(2):71-75.

11. Artnaseaw, A., Theerakulpisut, S.,Benjapiyaporn, C. Drying characteristics of Shiitake mushroom and Jinda chili during vacuum heat pump drying. Food Bioprod Process. 2010; 88(2):105-114.

12. Ghaboos, S.H.H., Ardabili, S.M.S., Kashaninejad, M., Asadi, G., Aalami, M. Combined infrared-vacuum drying of pumpkin slices. J Food Sci Technol. 2016; 53(5):2380-2388.

13. Duman, A.D. Storage of red chili pepper under hermetically sealed or vacuum conditions for preservation of its quality and prevention of mycotoxin occurrence. J Stored Prod Res. 2010; 46(3):155-160.

14. Mongpraneet, S., Abe, T., Tsurusaki, T. Accelerated drying of welsh onion by far infrared radiation under vacuum conditions. J Food Eng. 2002; 55(2):147-156.

15. Li, Y.H., Qi, Y.R., Wu, Z.F., Wang, Y.Q., Wang, X.C., Wang, F., Yang, M. Comparative study of microwavevacuum and vacuum drying on the drying characteristics, dissolution, physicochemical properties, and antioxidant capacity of Scutellaria extract powder. Powder Technol. 2017; 317:430-437.

16. ASABE. Standard for measurement of moisture in grin and seed. Agricultural Engineers Yearbook, 2005, 564-565
17. Kouchakzadeh, A., Shafeei, S. Modeling of microwaveconvective drying of pistachios. Energy Convers Manag. 2010; 51(10): 2012-2015.

18. Sledz, M., Wiktor, A., Nowacka, M., WitrowaRajchert, D. Drying kinetics, microstructure and antioxidant properties of Basil treated by ultrasound. J Food Process Eng.2017; 40(1).

19. Tummanichanont, C., Phoungchandang, S., Srzednicki, G. Effects of pretreatment and drying methods on drying characteristics and quality attributes of Andrographis paniculata. Journal of food processing and preservation. J Food Process Pres, 2017; 41(6): e13310.

20. Pilatti, D., Johann, G., Palú, F., Silva, E.A. Evaluation of a concentrated parameters mathematical model applied to drying of yerba mate leaves with variable mass transfer coefficient. Appl Therm Eng. 2016; 105:483-489.

21. Mujaffar, S., Loy, A.L. Drying Kinetics of MicrowaveDried Vegetable Amaranth (Amaranthusdubius) Leaves. J Food Res. 2016; 5(6):33.

22. Lemus-Mondaca, R., Vega-Gálvez, A., Moraga, N.O., Astudillo, S. Dehydration of Stevia rebaudianabertoni leaves: Kinetics, modeling and energy features. J Food Process Pres. 2015; 39(5):508-520.

23. Parlak N. Fluidized bed drying characteristics and modeling of ginger (zingiber officinale) slices. Heat Mass Transfer. 2015;51(8):1085-95.

24. Kaleta, A., Górnicki, K., Kościkiewicz, A. Influence of parameters of parsley root vacuum drying on kinetics of dried product rehydration. Inzynieria Rolnicza. 2006; 3(78):69-77.

25. Ren, G. Chen, F. Drying of American ginseng (Panaxquinquefolium roots by microwave-hot air combination. J Food Eng. 1998; 35(4):433-443. 